\title{
Spatio-Temporal Variation of Flushing Time in the Sumjin River Estuary
}

\author{
Dinesh Chandra Shaha ${ }^{1}$, Yang-Ki Cho ${ }^{1, *}$, Tae-Wan Kim ${ }^{2}$, and Arnoldo Valle-Levinson ${ }^{3}$ \\ ${ }^{1}$ School of Earth \& Environmental Sciences, Research Institute of Oceanography, Seoul National University, Seoul, Korea \\ ${ }^{2}$ Korea Polar Research Institute (KOPRI), Korea Ocean Research and Development Institute, Incheon, Korea \\ ${ }^{3}$ Department of Civil and Coastal Engineering, University of Florida, Gainesville, Florida, USA
}

Received 21 March 2011, accepted 22 August 2011

\begin{abstract}
Flushing is a very complicated process in estuarine environments. In order to examine the effects of tidal amplitude, river discharge, and stratification on the spatially varying flushing time of the Sumjin River Estuary (SRE), 24 longitudinal salinity transects were obtained during spring and neap tides from August 2004 to April 2007. The widely accepted freshwater fraction method has been used to calculate the flushing time for multiple estuarine segments using a spatially varying freshwater fraction. The effects of tidal amplitude, river discharge, and stratification on estuarine flushing were identified reasonably well by the spatially varying time scale. The flushing time appears to be close to the semidiurnal $\left(\mathrm{M}_{2}\right)$ tidal period during spring tide, but it is twice as long during a neap tide near the mouth. The flushing time increases in the central regions with a decrease in the tidal amplitudes and reduces in the inner-most regions owing to the strong influence of gravitational circulation. A linear function negatively relates estuarine flushing to the tidal amplitudes near the mouth of the estuary, whereas a power-law function relates estuarine flushing to the freshwater inflow near the head. In addition, strong stratification induced by freshwater discharge and small tidal amplitude exerts dominant control to reduce the estuarine flushing in the central and upper regions of the estuary during a neap tide.
\end{abstract}

Key words: Freshwater fraction method, Potential energy anomaly, Multiple segments, Spatio-temporal variations

Citation: Shaha, D. C., Y. K. Cho, T. W. Kim, and A. Valle-Levinson, 2012: Spatio-temporal variation of flushing time in the Sumjin River Estuary. Terr. Atmos. Ocean. Sci., 23, 119-130, doi: 10.3319/TAO.2011.08.22.01(Hy)

\section{INTRODUCTION}

The flushing time is an important indicator for the assessment of the estuarine water quality (Thomann and Muller 1987; Huang and Spaulding 2002; Huang 2007). It is commonly defined as the time required to replace the freshwater then present in the estuary (freshwater volume) at the rate of freshwater inflow (Officer 1976; Dyer 1997). In general, the flushing time of a given system depends on the tidal exchange between the system and the adjacent ocean which is a complicated function of the freshwater runoff, tidal range, density stratification, bathymetry, and wind (Pilson 1985; Choi and Lee 2004; Ji et al. 2007). The flushing time describes an overall feature of the estuary and is often used to estimate the removal rate of a pollutant carried by fresh water. A long flushing time implies that it would take a long time to flush pollutants from an estuary, which in turn may

\footnotetext{
* Corresponding author

E-mail:choyk@snu.ac.kr
}

involve outbreaks of harmful algal blooms (Garcon et al. 1986; Bricelj and Lonsdale 1997).

Several methods are used to calculate the flushing time, such as the freshwater fraction method (FFM), Knudsen's hydrographic theorem, tidal prism method, modified tidal prism method, and mixing length theory (Dyer 1997). In particular, the FFM has frequently been used to estimate the estuarine flushing time in response to freshwater inputs (Pilson 1985; Williams 1986; Dyer 1997; Huang 2007; Kumari and Rao 2009). This method determines the flushing time as the ratio between the freshwater volume of the estuary and the freshwater inflow rate (Officer 1976; Officer and Kester 1991; Dyer 1997; Ji 2008). This method is applicable only when detailed measurements of freshwater flow and salinity are available. Freshwater fraction models are most appropriate for estuaries where there is a measurable difference in the salinity between the estuary and the adjacent water body (Choi and Lee 2004; Valle-Levinson 2010). In general, the appropriateness of the estimation methods for flushing time 
depends on the relationship between the times interval over which salinity is sampled and that over which input flows are averaged (Pilson 1985). The effects of river discharge, wind, and water depth on the flushing time determined using the FFM were investigated by Pilson (1985), but the effects of tidal influences have not been assessed.

Alber and Sheldon (1999) extensively studied the temporal variability of flushing time for a number of Georgia estuaries in USA using the FFM where the estuary is considered as a whole. The effect of the river discharges was taken into account, but not the spatial variability in the flushing time. Williams (1986) used the FFM to calculate the flushing times for different parts of the upper Waitemata Harbor in order to understand the effects of freshwater input on the flushing time, because freshwater is discharged into the upper harbor from a number of points instead of a single point source. In addition, Monsen et al. (2002) reported that no single flushing time is valid for all time periods, locations, and constituents of an estuarine system. This implies that a spatially varying estuarine time scale is more appropriate to understand the effects of freshwater discharge and tidal amplitude on the estuarine water quality. In this study, the flushing times for a number of segments of the Sumjin River Estuary (SRE) are determined using the FFM with a spatially varying freshwater fraction in order to examine the effects of freshwater discharge and tidal amplitude on the spatially varying flushing time. In addition, the effect of stratification on estuarine flushing has been examined.

This paper is organized as follows. The study area and data are briefly presented in section 2 . The methodology is described in section 3. Results are presented in section 4. A discussion follows in section 5 , and conclusions are given in section 6 .

\section{STUDY AREA AND DATA}

The Sumjin River discharges into Gwangyang Bay on the south coast of Korea. The bay is connected in the south to the coastal ocean (South Sea) and in the east to Jinjoo Bay through the narrow Noryang Channel (Fig. 1). The watershed area of the Sumjin River Estuary, including farmland, is almost $4900 \mathrm{~km}^{2}$. Seasonal precipitation and runoff in the Sumjin River basin decrease in spring and winter, but increase in summer (Bae et al. 2008). The daily mean river discharge rates were obtained from the Songjung gauge station, located about $11 \mathrm{~km}$ upstream from CTD station 24 . The maximum monthly median river discharge rate was highest $\left(370 \mathrm{~m}^{3} \mathrm{~s}^{-1}\right)$ in July 2006 and lowest $\left(11 \mathrm{~m}^{3} \mathrm{~s}^{-1}\right)$ in January 2005.

Tidal information has been collected from the Gwangyang Tidal Station (GT1, Fig. 1) operated by the Korea Hydrographic and Oceanographic Administration during the observation period. The tidal cycle is semi-diurnal, with mean spring and neap ranges of 3.40 and $1.10 \mathrm{~m}$, respec- tively. The tidal constituents for station GT2 (see location in Fig. 1) were obtained from the Korean Ocean Research \& Development Institute (http://www.kordi.re.kr/odmd/har monic2004/). Tidal constituents observed in July 2001 at the Mangdock (MD) station were obtained from the Pohang Iron and Steel Company (Lee 2002). The $\mathrm{M}_{2}$ tide is the primary tidal constituent at the mouth. Sea level data for 2005 and 2006 from the Hadong tidal (HT) gauge station (http://www.wamis.go.kr/wkw/WL DUBWLOBS.ASPX) were analyzed using the Task-2000 tidal package developed by the Proudman Oceanographic Laboratory (Bell et al. 1999).

Conductivity-temperature-depth (CTD) profiles were measured using an Ocean Seven 304 CTD probe (IDRONAUT Co.) at 24 locations along the SRE. The nominal distance between the CTD stations was $1 \mathrm{~km}$. A total of 24 longitudinal salinity transects were obtained at high water during spring and neap tides in each season from August 2004 to April 2007. The global positioning system was used

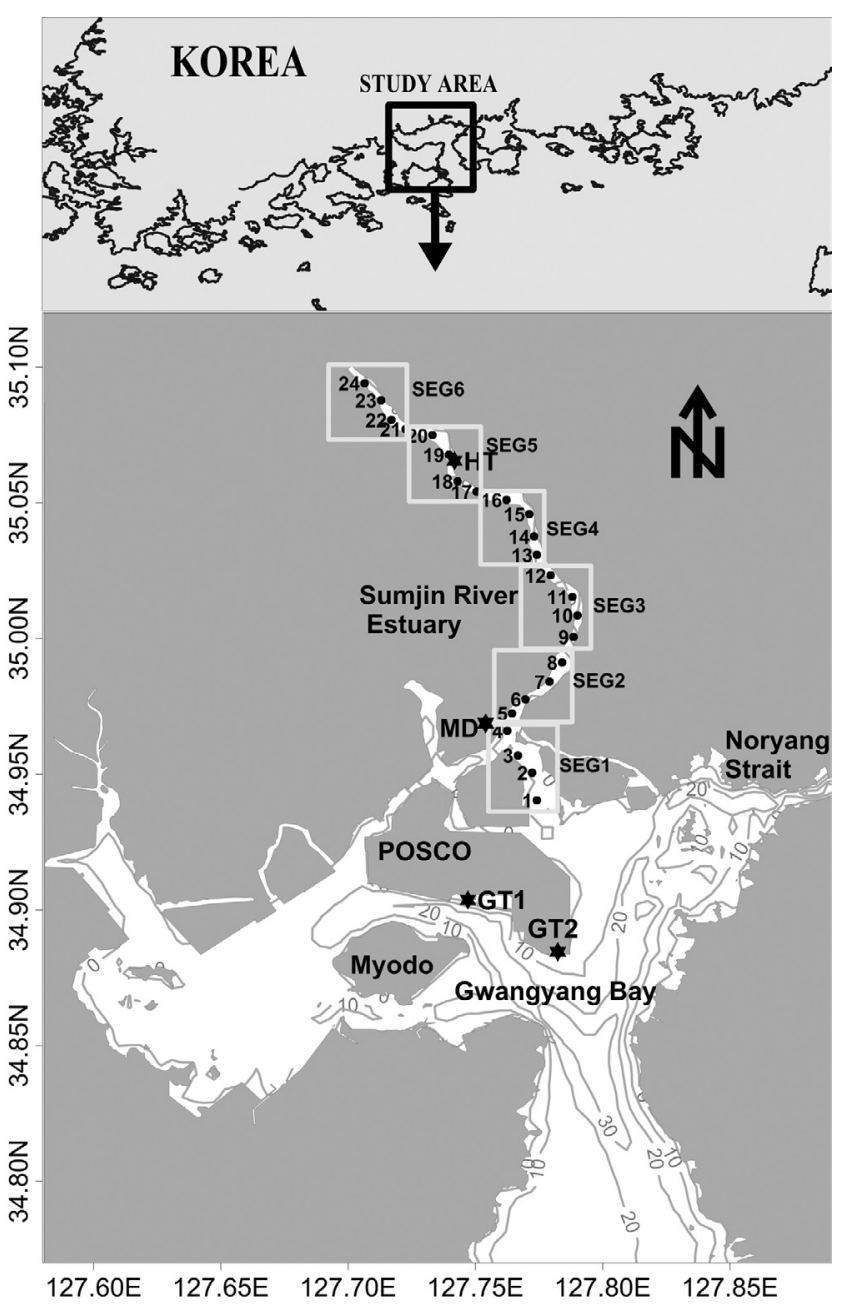

Fig. 1. Map of study area. Solid circles indicate CTD stations. Stars denote the Gwangyang (GT1 and GT2), Mangdock (MD), and Hadong (HT) tidal observation stations. 
to ascertain the locations of the CTD stations. According to stratification parameter, which is the difference between the surface and bottom salinities divided by the depth averaged salinity, the SRE undergoes a transition from being partially or well-mixed at spring tide to being stratified at neap tide (Shaha and Cho 2009).

\subsection{Segment Information}

Bathymetric data were collected from the Regional Construction and Management Office of the Construction Department, Korean Ministry of Construction and Transportation. The extended trapezoidal, extended Simpson's, and extended Simpson's 3/8 rules (Press et al. 1988) were used to determine the volume $\left(V_{i}\right)$ of each segment at high water during both spring and neap tides. The mean sea level depth was converted to an approximate high water depth by adding the relevant half-tide height for both spring and neap tides. The high water depths $H(x, y)$ were used to calculate the segment volumes as follows:

$V_{i}=\int_{x_{\min }}^{x_{\max }} \int_{y_{\min }}^{y_{\max }} H(x, y) d x d y$

where $x$ is the along-estuary distance and $y$ is the crossestuary distance. Table 1 lists the volumes $\left(V_{i}\right)$ and depths of each segment of the SRE during both spring and neap tides. The volume of each segment ranges from $2.1 \times 10^{6} \mathrm{~m}^{3}$ (SEG6) to $14.3 \times 10^{6} \mathrm{~m}^{3}$ (SEG1). SEG3 is deeper and narrower than the others.

Four CTD stations were allocated to each segment. The mean salinity value $\left(S_{i}\right)$ of each segment $\left(S_{i}\right)$ was calculated from that of its four CTD stations by using their vertical salinity profiles for each survey day. The salinity of the seawater that enters the estuary via Gwangyang Bay varies with time. CTD station-1 was selected as a reference value of the salinity of the sea-water $\left(S_{s w}\right)$ entering the bottom of the estuary mouth on each survey day.

\section{FRESHWATER FRACTION METHOD (FFM)}

The flushing time of the SRE can be determined from the estuarine geometry, freshwater runoff, and salinity measurements (three years) by the FFM, using salinity as a tracer. In general, the flushing time $(T)$ is calculated by the FFM as described by Officer (1976), Williams (1986), and Dyer (1997):

$T=\frac{F}{Q_{f}}=\frac{\sum_{i=1}^{n} F_{i}}{Q_{f}}=\frac{\sum_{i=1}^{n} f_{i} V_{i}}{Q_{f}}=\frac{1}{Q_{f}} \sum_{i=1}^{n}\left(1-\frac{S_{i}}{S_{s w}}\right) V_{i}$

where $F$ is the accumulated freshwater volume in the estu- ary, $Q_{f}$ is the freshwater discharge rate, $F_{i}$ is the freshwater volume of the $i$ th segment, $S_{s w}$ is the seawater salinity outside the estuary mouth, $S_{i}$ is the mean salinity of the $i$ th segment, and $n$ is the total number of estuary segments. The freshwater volume $\left(F_{i}\right)$ of each segment was calculated by multiplying the freshwater fraction $\left(f_{i}\right)$ of each segment by the volume $\left(V_{i}\right)$ of that segment. The total freshwater volume $(F)$ of the estuary is calculated by summing the freshwater volume over all segments. This sum was then divided by the freshwater input to determine the flushing time of the entire estuary. The freshwater fraction approach may be applied not only to an entire estuary, as in Eq. (2) but also to several connected estuary segments (Williams 1986; ValleLevinson 2010) where the estuary flushing time is the sum of the flushing times for all the segments. The flushing time $\left(T_{i}\right)$ of each estuarine segment can then be calculated as follows:

$T_{i}=\frac{V_{i}}{Q_{f}}\left(1-\frac{S_{i}}{S_{s w}}\right)=\frac{F_{i}}{Q_{f}}$

Each time scale can be considered as the average time for freshwater to pass through a segment. Although either flushing time equation appears to entail a straightforward steady-state calculation, the choice of freshwater discharge rate $Q_{f}$ can be problematic, because the river discharge is rarely in a steady state (Alber and Sheldon 1999). Some investigators use the river discharge on the actual date of field observation (Balls 1994; Eyre and Twigg 1997), some use the river discharge averaged over a number of days prior to field observation (Atkinson et al. 1978), and still others use monthly or seasonally averaged flows (Pilson 1985; Lebo et al. 1994). Each of these approaches results in a different estimate of the flushing time. In this study, the flushing times for the SRE were calculated using the median river discharge both over the tidal cycle on the day of field observation and over 14 tidal cycles prior to the field observation. The constant value of $Q_{f}$ has been assumed for each segment. The flushing time of the entire estuary was considered as a single flushing time while the segment flushing times

Table 1. Volumes and depths of six segments of the Sumjin River Estuary at high water during both spring and neap tides.

\begin{tabular}{cccccc}
\hline \multirow{2}{*}{ Segment } & \multicolumn{2}{c}{ Depth $(\mathbf{m})$} & & \multicolumn{2}{c}{ Volume $\left(\mathbf{1 0}^{\mathbf{6}} \mathbf{~ m}^{3}\right)$} \\
\cline { 2 - 3 } \cline { 5 - 6 } & Spring & Neap & & Spring & Neap \\
\hline SEG1 & 6.1 & 5.2 & & 14.3 & 11.8 \\
SEG2 & 7.3 & 6.4 & & 9.3 & 7.9 \\
SEG3 & 8.0 & 7.1 & & 10.4 & 8.9 \\
SEG4 & 5.1 & 4.2 & & 8.5 & 6.7 \\
SEG5 & 2.7 & 2.5 & & 3.6 & 3.1 \\
SEG6 & 2.4 & 2.4 & & 2.1 & 2.1 \\
\hline
\end{tabular}


were regarded as a spatially varying flushing time. The temporal variation in the single flushing time has been studied intensively in terms of freshwater discharge (Pilson 1985; Alber and Sheldon 1999) and wind (Pilson 1985). In this study, emphasis is placed on the spatially varying flushing time in order to examine how it is affected by freshwater discharge, tidal amplitude, and stratification.

The data were analyzed as a function of two main forcing factors: river discharge rate and high water level (a proxy for a tidal cycle). General regressions of flushing times with freshwater input and high water levels were used to understand the physical and hydrological processes for this estuarine system. Simple power-law and linear functions were used to examine the effects of freshwater inflow and tidal amplitude on the spatial heterogeneity of estuarine flushing. Subsequently, the influences of stratification on the spatial heterogeneity of estuarine flushing were described in terms of the potential energy anomaly in the water column. Although, in general, wind may affect the strength of estuarine circulation, it has negligible effect on the flow for an estuary with a width of $<1 \mathrm{~km}$ (Ji 2008). The effect of remote wind on flushing remains to be determined from time series measurements. In this study, wind effects were not considered owing to narrowing of the SRE.

\section{RESULTS AND DISCUSSION}

\subsection{Freshwater Fraction and Single Flushing Time}

The freshwater fraction increases from downstream to upstream in all seasons. High values of freshwater fraction were found in summer along with high river discharge (Fig. 2). This indicates that increased river flow in summer causes a rapid exchange of freshwater with bay. Low values of freshwater fraction in winter are a result of low river discharge and indicate a dominant upstream movement of seawater. This result is consistent with that of Kumari and Rao (2009). In addition, the freshwater fraction varies near the mouth according to the strength of the spring-neap tidal cycles.

The temporal variation in a single flushing time is given in Table 2. The single flushing time varies from 4.4 to 12.2 days, with an average of 7.1 and 7.0 days, at spring and neap tides, respectively. In this study, there was no significant difference between the flushing time calculated with the median river discharge over the tidal cycle on the day of field observation and that calculated over 14 tidal cycles prior to the field observation. The power-law function satisfactorily relates the single flushing time to the river discharges rates (Fig. 3a). However, no significant correlation was found between the single flushing time and high water level (Fig. 3b). Thus, a single flushing time describes the general exchange characteristics of the SRE with the influence of river discharge. Such a single time scale might be appropriate to compare the general characteristics of different water systems, as done by Alber and Sheldon (1999) for five riverine estuaries in Georgia, USA. However, the spatially varying local measure of flushing time within an estuarine system provides more information about the mechanisms of spatial heterogeneity.

\subsection{Spatial Variation of Flushing Time}

To investigate the effects of tidal amplitude, river discharge, and stratification on the spatial heterogeneity of estuarine flushing, the freshwater fraction method was applied to multiple segments of the SRE. The segment flushing time varies with the rates of changes in the freshwater inflow, estuarine circulation, and tidal amplitude. The temporal varia- (a)

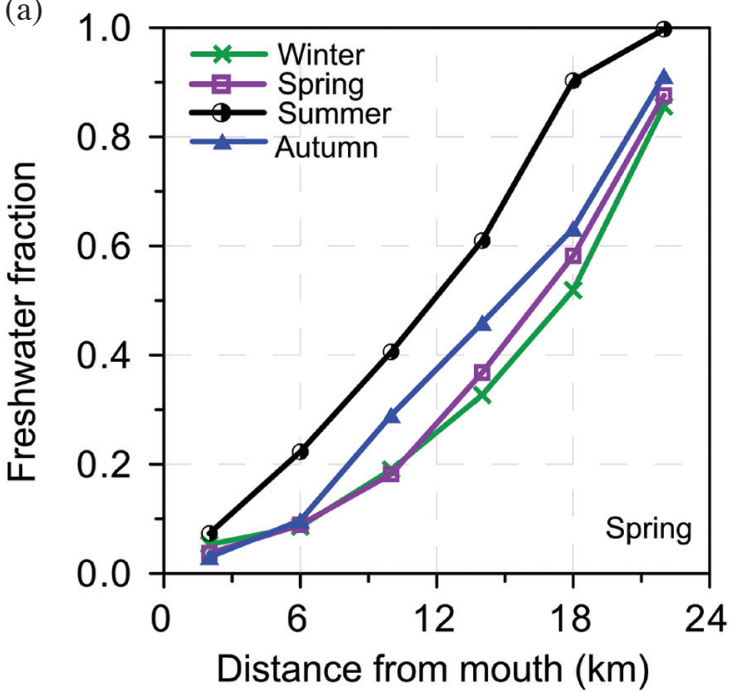

(b)

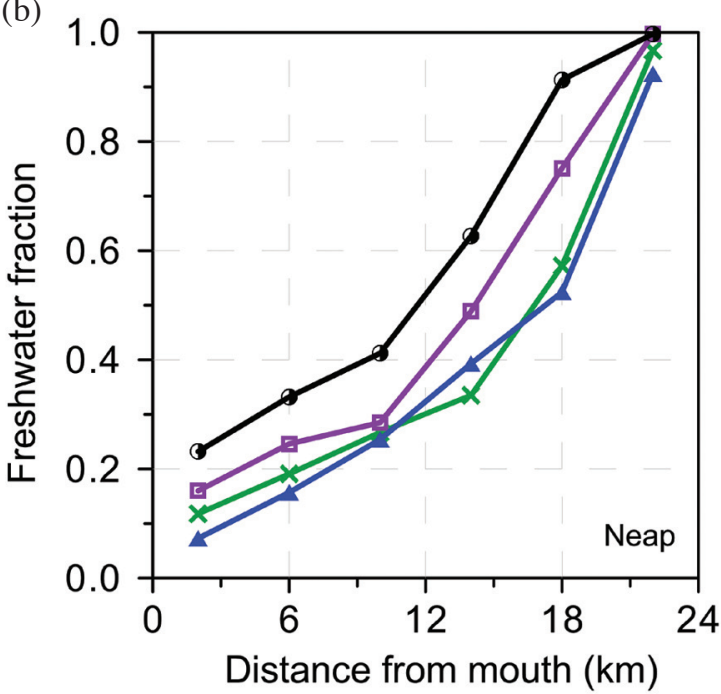

Fig. 2. Spatial variation in freshwater fraction $\left(1-S_{i} / S_{s w}\right)$ along the Sumjin River Estuary during (a) spring tide and (b) neap tide. 
Table 2. Median flushing times for median river discharges over the $\mathbf{M}_{2}$ tidal period during spring and neap tides.

\begin{tabular}{|c|c|c|c|c|c|c|c|}
\hline \multirow[b]{2}{*}{ Year } & \multirow[b]{2}{*}{ Season } & \multicolumn{3}{|c|}{ Spring tide } & \multicolumn{3}{|c|}{ Neap tide } \\
\hline & & $\begin{array}{l}\text { River discharge } \\
\qquad\left(\mathrm{m}^{3} \mathbf{s}^{-1}\right)\end{array}$ & $\begin{array}{l}\text { Tidal range } \\
\text { (m) }\end{array}$ & $\begin{array}{l}\text { Flushing time } \\
\text { (days) }\end{array}$ & $\begin{array}{c}\text { River discharge } \\
\qquad\left(\mathbf{m}^{3} \mathbf{s}^{-1}\right)\end{array}$ & $\begin{array}{l}\text { Tidal range } \\
\text { (m) }\end{array}$ & $\begin{array}{l}\text { Flushing time } \\
\text { (days) }\end{array}$ \\
\hline 2004 & Summer & 46 & 3.09 & 4.4 & 26 & 1.22 & 7.5 \\
\hline 2004 & Autumn & 29 & 3.86 & 6.2 & 22 & 1.60 & 6.6 \\
\hline 2005 & Winter & 10 & 3.14 & 12.2 & 16 & 1.04 & 10.4 \\
\hline 2005 & Spring & 18 & 3.51 & 7.1 & 26 & 0.73 & 6.8 \\
\hline 2005 & Summer & 58 & 2.45 & 7.0 & 77 & 1.20 & 3.6 \\
\hline 2005 & Autumn & 16 & 3.92 & 11.4 & 13 & 0.97 & 9.2 \\
\hline 2006 & Winter & 19 & 3.17 & 5.4 & 14 & 1.12 & 9.8 \\
\hline 2006 & Spring & 11 & 3.84 & 7.0 & 30 & 0.52 & 6.1 \\
\hline 2006 & Summer & 50 & 2.93 & 4.9 & 44 & 0.92 & 5.1 \\
\hline 2006 & Autumn & 9 & 3.99 & 11.3 & 15 & 1.87 & 6.2 \\
\hline 2007 & Winter & 12 & 3.85 & 8.1 & 11 & 1.32 & 11.2 \\
\hline 2007 & Spring & 21 & 3.03 & 7.4 & 14 & 0.84 & 9.6 \\
\hline
\end{tabular}
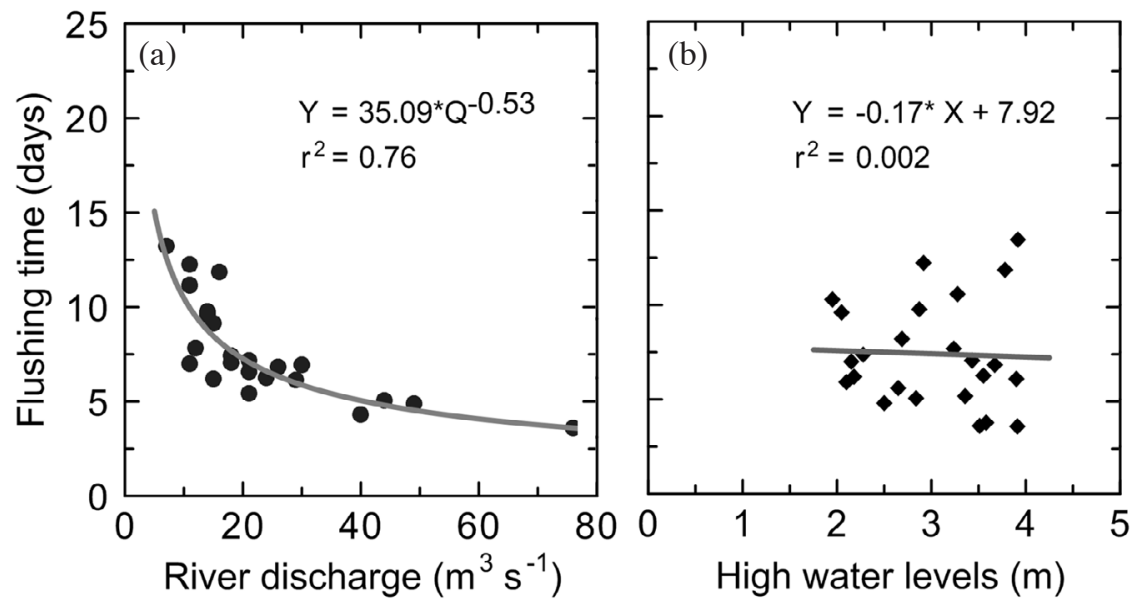

Fig. 3. (a) Power-law function between single flushing time and river discharge, and (b) linear function between single flushing time and high water levels, where flushing time was calculated using Eq. (2).

tions in the segment flushing times during spring and neap tides are presented in Fig. 4. In general, the flushing time of SEG1 is shorter than the $\mathrm{M}_{2}$ tidal period and that of SEG2 is longer than the $\mathrm{M}_{2}$ tidal period (Fig. 4a). The flushing time increases in the central regions (SEG3 and SEG4) and then decreases in the inner regions (SEG5 and SEG6). The flushing times of SEG1 and SEG2 at neap tide are mostly shorter than twice the $\mathrm{M}_{2}$ tidal period (Fig. 4b). Although the flushing time increases in the central regions during neap tide, it remains shorter than that during spring tide.

Figure 5 shows the spatial variations in the mean segment flushing times during spring and neap tides, thus implicitly including the spring-neap variation. In both SEG1 and SEG2 the flushing time during spring tide is longer than during neap tide, because of the larger tidal amplitude during spring tide. By contrast, in SEG4 and SEG5 the flush- ing time during neap tide is shorter than that during spring tide. It is well known that a reduction in tidal amplitude enhances the estuarine circulation, which increases the water exchange (Nunes Vaz et al. 1989; Monismith et al. 1996; Valle-Levinson 2010) and reduces the estuarine flushing time.

The major tidal constituents $\left(\mathrm{M}_{2}, \mathrm{~S}_{2}, \mathrm{~K}_{1}\right.$, and $\left.\mathrm{O}_{1}\right)$ are listed in Table 3 to indicate the differences in tidal amplitude between the mouth and head of the estuary. The tidal amplitudes of the $\mathrm{M}_{2}$ and $\mathrm{S}_{2}$ constituents decrease by $12 \%$ and $8 \%$, respectively, within the estuary between stations GT2 and HT (Table 3). Yanagi and Abe (2005) found that an increase in water exchange results from an intensification of gravitational circulation due to a decrease in tidal amplitude. According to the stratification parameter, the SRE exhibits strong stratification during neap tide (Shaha and Cho 
2009). A link develops between stratification and gravitational circulation during neap tide because of significantly reduced vertical mixing due to weakened bottom friction (Nunes Vaz et al. 1989; Monismith et al. 1996). Therefore, in the central and inner regions of the SRE a strong gravitational circulation might reduce the flushing time at neap tide as compared to that at spring tide. Thus, the variation in the tidal amplitude with the spring-neap cycle causes a springneap variation in the flushing time of the SRE.

The flushing times of the different segments were plotted against the river discharge to examine the effects of freshwater inflow on the spatial heterogeneity of estua-
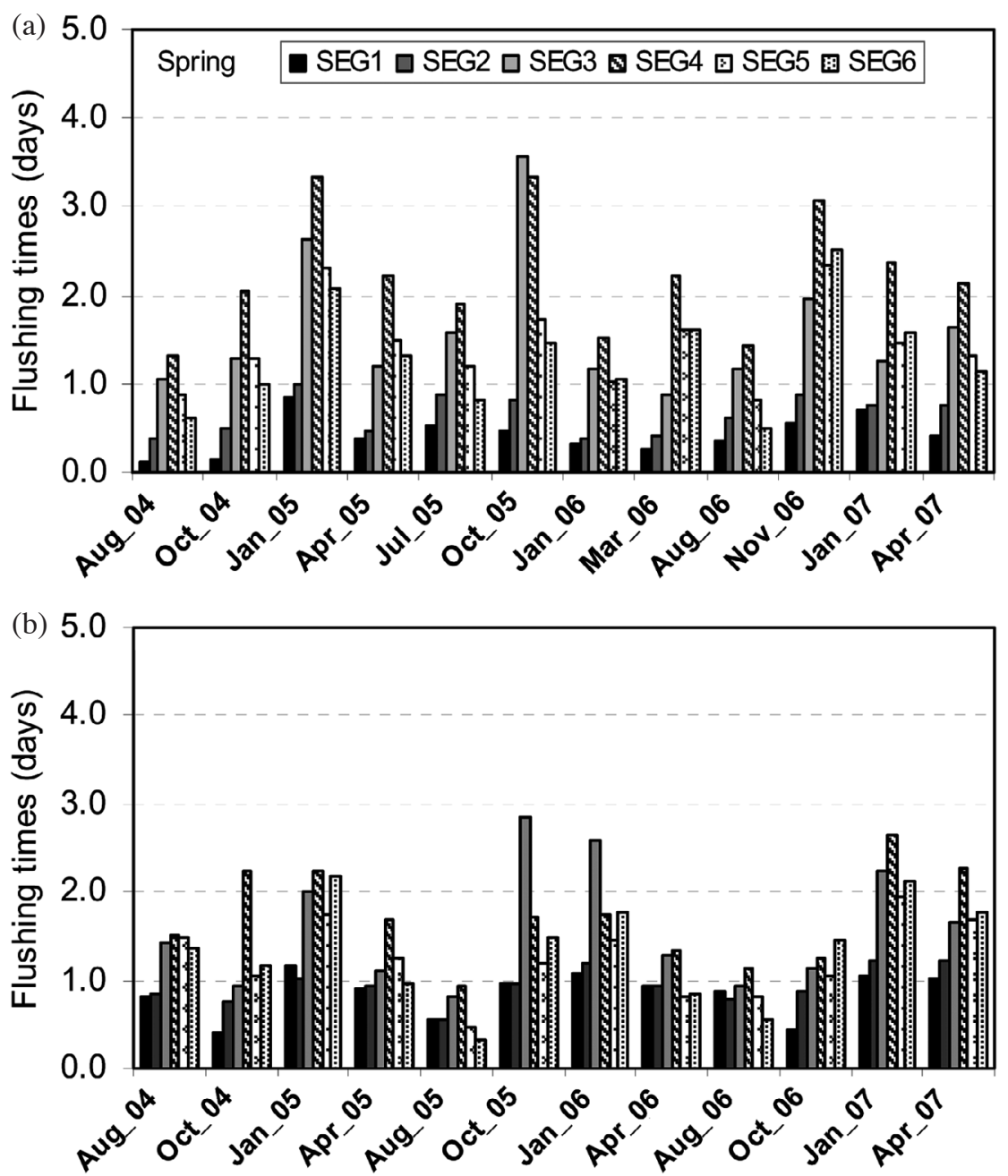

Fig. 4. Flushing times for multiple estuarine segments during (a) spring and (b) neap tides from August 2004 to April 2007, calculated with Eq. (3).

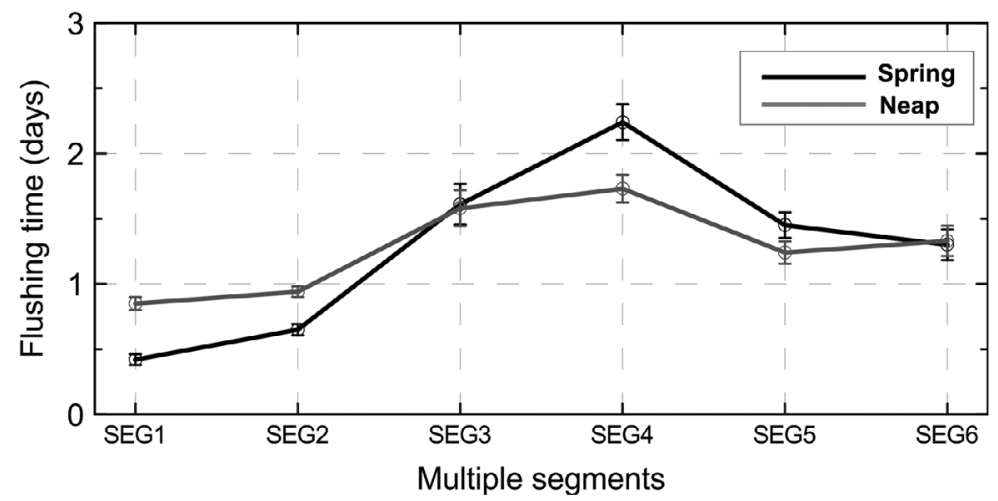

Fig. 5. Spatial variation in median segment flushing times along the Sumjin River Estuary during spring and neap tides. 
Table 3. Tidal amplitudes observed at the Gwangyang (GT), Mangdock (MD), and Hadong (HT) tidal stations.

\begin{tabular}{ccccc}
\hline \multirow{2}{*}{$\begin{array}{c}\text { Tidal } \\
\text { station }\end{array}$} & \multicolumn{4}{c}{ Amplitude (cm) } \\
\cline { 2 - 5 } & $\mathbf{M}_{2}$ & $\mathbf{S}_{2}$ & $\mathbf{K}_{1}$ & $\mathbf{O}_{1}$ \\
\hline GT1 & 108.0 & 50.3 & 19.5 & 13.3 \\
GT2 & 109.3 & 46.7 & 18.7 & 14.3 \\
MD & 107.8 & 44.2 & 18.8 & 14.5 \\
HT & 96.6 & 42.8 & 17.9 & 11.9 \\
\hline
\end{tabular}

rine flushing (Fig. 6). The best fit to the data is obtained with a power-law function, not an exponential function. The flushing time is quite sensitive (changes rapidly) at low freshwater discharges rates $\left(<30 \mathrm{~m}^{3} \mathrm{~s}^{-1}\right)$. As expected, the shortest flushing times are associated with the largest flow rates (Alber and Sheldon 1999). The correlation coefficient $R^{2}$ sequentially decreases from its highest value of 0.95 in SEG6 (upper estuary) to its lowest value of 0.07 in SEG1 (lower estuary). The $R^{2}$ value at SEG5 and SEG6 (upstream) is maximal because this region is dominated by freshwater, with the value of freshwater fraction close to 1 . On the other
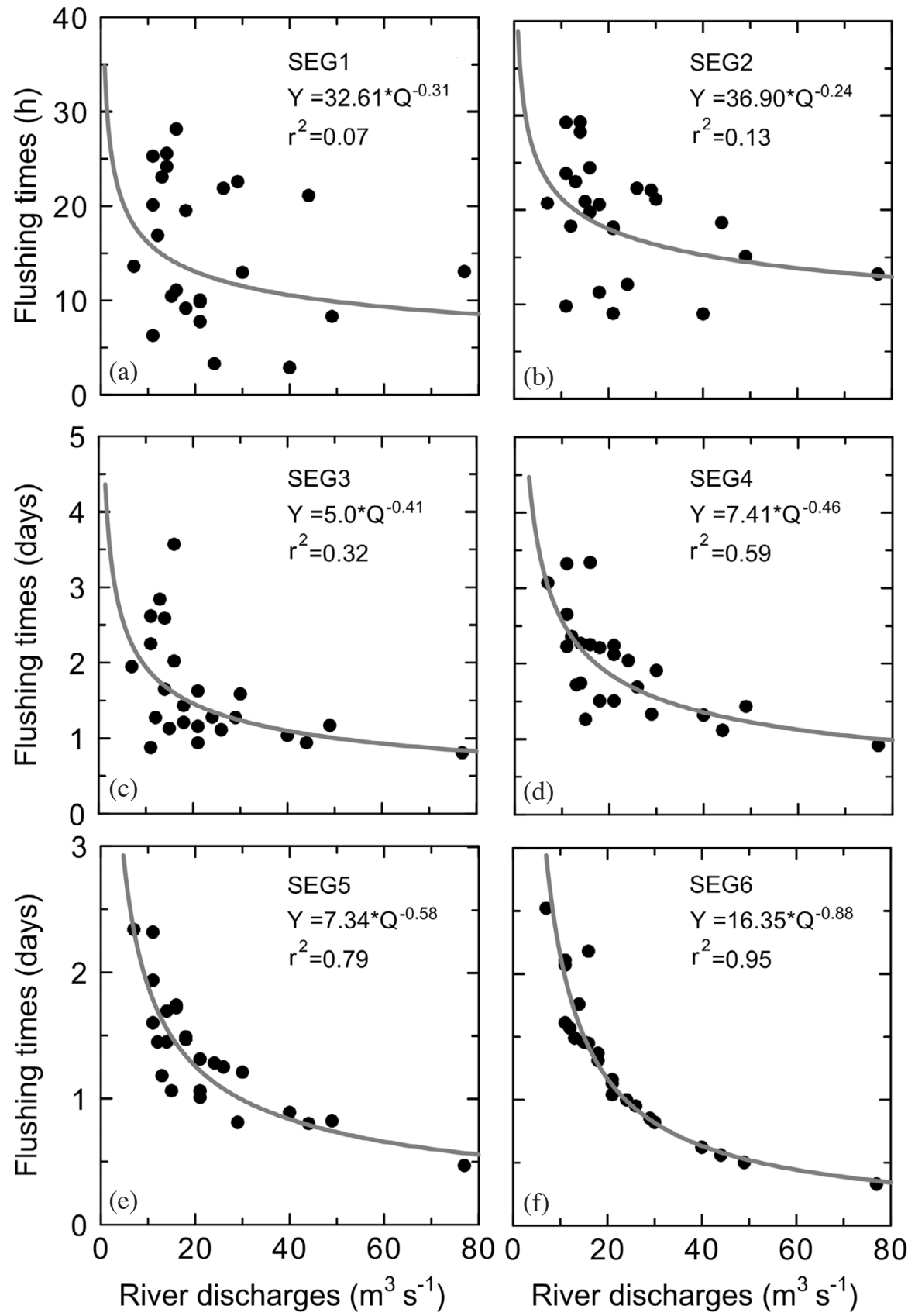

Fig. 6. Comparison of the power-law function between flushing time $(T)$ and river discharge $(Q)$ for multiple estuarine segments: (a) (b) down estuary, (c) (d) middle estuary, and (e) (f) upper estuary. 
hand, since the freshwater volume near the mouth is largely influenced by tides, the flushing times of SEG1 and SEG2 exhibit broad scatter due to approaching the value of freshwater fraction close to 0 and gives lower level of $R^{2}$ value. The length of SEG1 and SEG2 is roughly equivalent to the maximum tidal excursion observed (Shaha and Cho 2009). In most previous studies of the freshwater fraction method, a single time scale has been considered that demonstrates only the influences of freshwater discharge (Pilson 1985; Alber and Sheldon 1999; Kumari and Rao 2009) and wind (Pilson 1985). In this study, however, the power-law func- tion relates the estuarine flushing to the freshwater inputs at the upstream end, with higher correlation coefficients, but proves ineffective near the mouth where the tidal effect is dominant.

To help understanding the physical and hydrological processes of the SRE, a linear regression of flushing time on high water level is shown in Fig. 7. A linear function with negative slope appears between the flushing time and the high water level, with correlation coefficients of 0.64 and 0.48, in SEG1 (Fig. 7a) and SEG2 (Fig. 7b), respectively. According to Eq. (2), if the segment salinity $S_{i}$ is
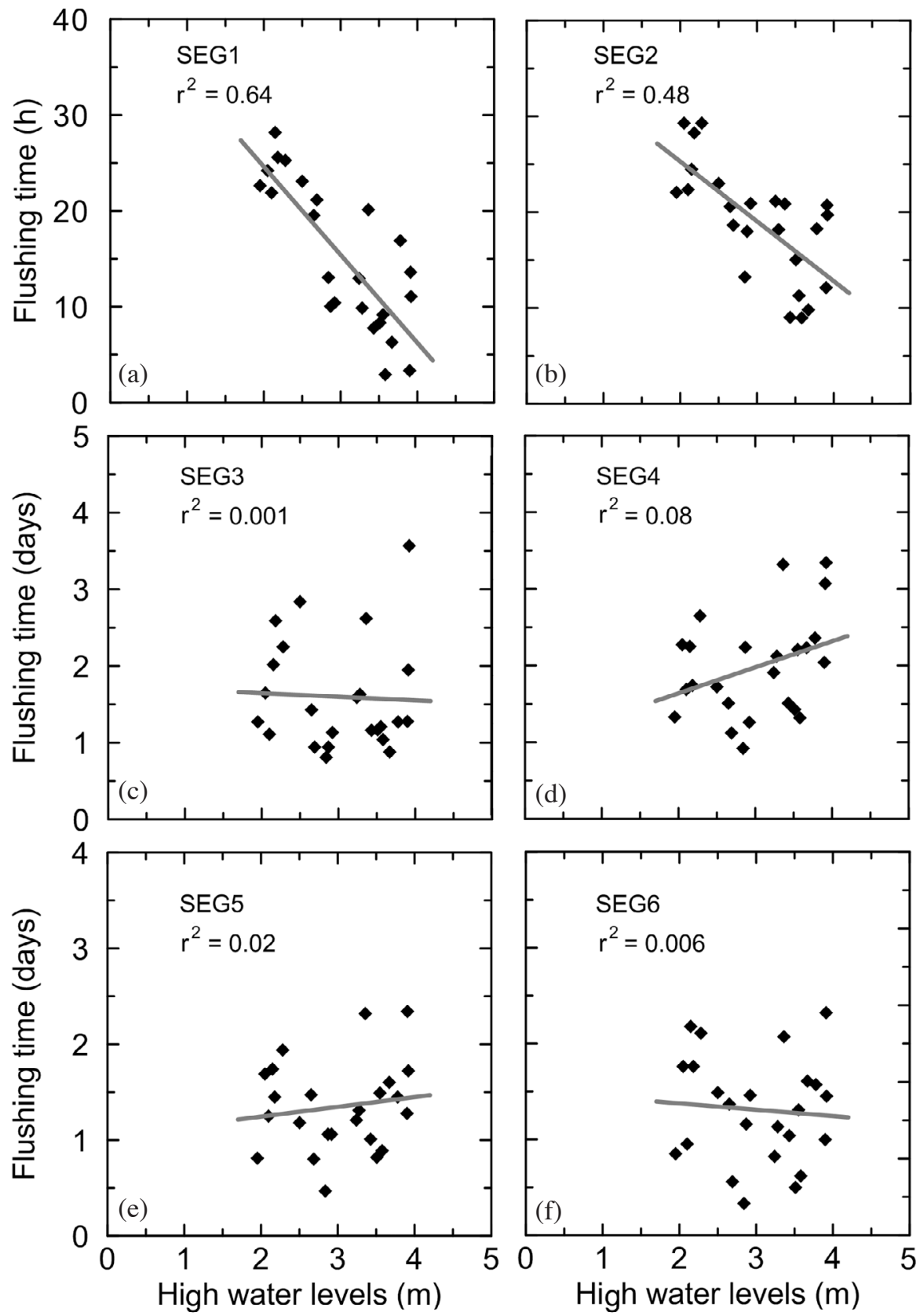

Fig. 7. Comparison of the linear function between flushing time ( $T$ ) and high water levels for multiple estuarine segments: (a) (b) down estuary, (c) (d) middle estuary and (e) (f) upper estuary. 
close to the seawater salinity $S_{s w}$, the flushing time becomes shorter. As SEG1 and SEG2 are close to the mouth of the SRE (downstream), $S_{i}$ is close to $S_{s w}$ due to the strong tidal effects. As a result the flushing time at SEG1 and SEG2 is shorter. Therefore, $R^{2}$ value between the flushing time and the high water level appears maximal at SEG1 and SEG2. However, no significant correlation appears in the remaining segments (Figs. 7c- f). According to this regression analysis, the flushing time in the lower estuary (SEG1 and SEG2) depends to a great extent on tidal amplitude, and to a lesser extent on freshwater input. Further upstream, the flushing time in the SRE greatly depends on gravitational circulation, which is induced by the reduced tidal amplitude and the freshwater input. Thus, the calculation of flushing times for multiple segments of the SRE reveals the spatial variations in freshwater discharge and tidal effects.

\subsection{Relationship Between Stratification and Flushing Time}

The flushing time varies depending upon $Q_{f}, V_{i}$ and (1- $\left.S_{i} / S_{s w}\right)$ as described in Eq. (2). The volume of each seg- ment $V_{i}$ varies according to the height of the spring and neap tide. Among these, the freshwater fraction $\left(1-S_{i} / S_{s w}\right)$ is the most important factor that controls the flushing time. If $S_{i}$ is close to $S_{s w}$, the flushing time becomes shorter. This is the case found at SEG1 and SEG2 near the mouth of the SRE (downstream) where $S_{i}$ is close to $S_{s w}$ due to strong tidal mixing. As a result, the flushing time is shorter at SEG1 and SEG2 (Fig. 8, upper). On the other hand, the flushing time in the upstream (SEG5 and SEG6) dominated by freshwater is longer because the horizontal salinity gradient in the upstream is larger than at the estuary mouth. The flushing times at SEG3 and SEG4 are longer than the flushing time at SEG5 and SEG6. This situation might occur as volumes $\left(V_{i}\right)$ of SEG3 and SEG4 is larger than those of SEG5 and SEG6.

The influences of the reduction in tidal amplitude on the water column stratification and estuarine flushing are described by calculating the potential energy anomaly of the water column (Simpson et al. 1990; de Boer et al. 2008). The potential energy anomaly $\phi$ of the water column was calculated for each CTD station to determine any temporal or spatial variability of the water column stratification that
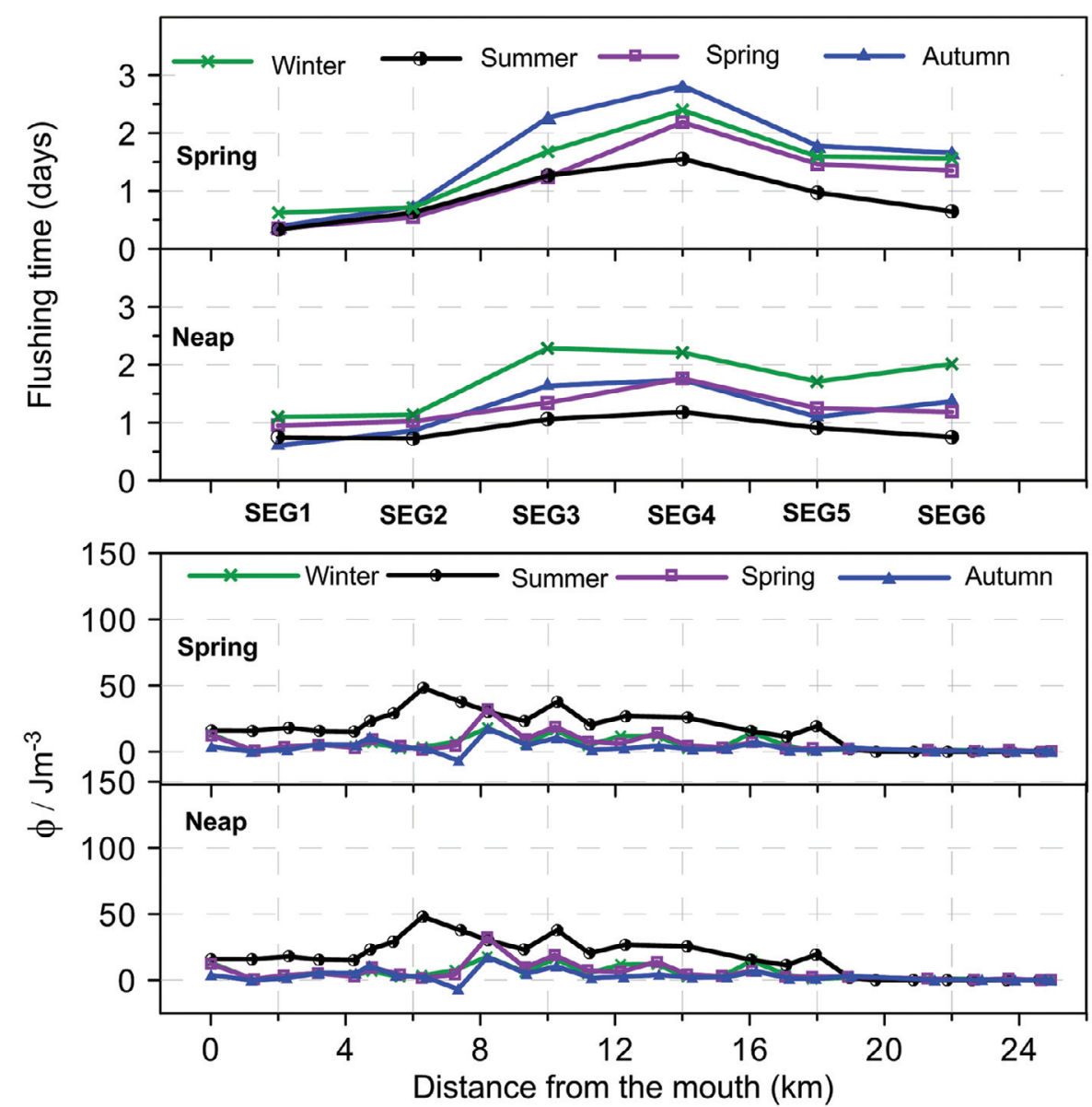

Fig. 8. Seasonal variation of flushing times (upper panel) and a potential energy anomaly $\phi$ (lower panel) along the Sumjin River Estuary during spring and neap tides. 
might influence the estuarine flushing. Following the approaches of Simpson et al. (1990) and de Boer et al. (2008), the potential energy anomaly is the amount of work $\left(\mathrm{J} \mathrm{m}^{-3}\right)$ necessary to completely mix the water column. This can be calculated from

$$
\phi=\frac{1}{H} \int_{-H}^{0} g z(\bar{\rho}-\rho) d z
$$

with the depth averaged density

$$
\bar{\rho}=\frac{1}{H} \int_{-H}^{0} \rho d z
$$

where $\rho$ is a given vertical density profile, $H$ is the depth of the water column, $z$ is the vertical co-ordinate, and $g$ is the gravitational acceleration $\left(9.8 \mathrm{~m} \mathrm{~s}^{-2}\right)$.

The amount of $\phi$ in the water column increases in summer during both spring and neap tides due to increasing river discharge. The lighter dense water at the surface layer induced by increasing river discharge and heavier dense water at the lower layer enhances the estuarine circulation in summer. As a result the flushing time lessens in summer during both spring and neap tides (Fig. 8). Due to the strong tidal amplitude during spring tide the flushing time of the spring tide is shorter than that of the neap tide near the mouth (SEG1 and SEG2). $\phi$ is low at SEG1 and SEG2 (downstream) during spring tide due to homogeneous density (well mixed) caused by strong tidal current. On the other hand, $\phi$ is high at SEG1 and SEG2 (downstream) during neap tide due to strongly stratified water, caused by large freshwater input in upper layer and weak tide. This result indicates that the tidal amplitude is the dominant factor near the mouth to control the flushing time. Banas and Hickey (2005) also found that the shortest time scale of $\sim 3$ days (average time over spring-neap tidal cycle) occurs at the entrance of seawater to Willapa Bay due to the tidal forcing and the longest time scale of 36 days at the upstream end.

$\phi$ is low near the upstream and downstream of the estuary, but relatively high in the middle region (SEG3 and SEG4) where the freshwater and tidal-induced saline water collide (Fig. 8, lower). In winter, the flushing time of the neap tide is little bit longer than that of the spring tide. However, the flushing time at neap tide in summer, autumn and spring is shorter than that at spring tide in the middle region because of high $\phi$ in the water column. Increased values of $\phi$ in the water column represent strong stratified conditions during neap tide. A particularly interesting aspect of the highly stratified estuary is the intensification of the circulation produced by the entrainment process (Dyer 1997; Valle-Levinson 2010). An amount of freshwater $(Q)$ enters the estuary at its head during a tidal cycle. This water moves towards the sea in the upper layer. Entrainment from the lower layer adds saltwater to the upper layer, increasing the volume transport of the upper layer. If this process continues, the volume transport in the upper layer increases to several times than the freshwater volume from the upstream. Therefore, the flushing time lessens during neap tide than that during spring tide in the middle region. Chant et al. (2007) also reported that an ejection of surface waters is most pronounced at neap tide when an estuary is highly stratified.

$\phi$ is low at SEG5 and SEG6 (upstream) during spring and neap tides due to homogenous density by freshwater intrusion. The calculation of flushing time for multiple estuarine segments provides more information about the local processes and yields valuable clues about the mechanisms of the spatial heterogeneity.

\section{CONCLUSION}

A single time scale, which is a system-wide indicator of renewal capacity, can be used to evaluate the effect of freshwater discharge on estuarine flushing, but not resolve the influence of tidal forcing. However, a spatially varying time scale can be used to determine the spatial variation in flushing properties for various environmental factors, such as the effects of tidal amplitude, stratification, and freshwater discharge.

The flushing time near the mouth is shorter during spring tide than during neap tide because of the larger amplitude of the spring tide. A linear function with a negative slope relates the estuarine flushing to the tidal amplitudes near the mouth. At the estuary mouth, the potential energy anomaly of the water column is negligible. In the upstream segments (SEG3 to SEG6), the flushing times are shorter during the neap tide than during the spring tide because of relatively increased gravitational circulation which occurs due to the reduction in tidal amplitude. As a result, the flushing time shows a strong correlation with the upstream river discharge.

The results suggest that it is more reasonable to use a spatially varying local time scale, rather than a single time scale, to investigate the effects of tidal amplitude, river discharge, and stratification on spatially varying estuarine flushing. The spatially varying local time scale provides a deeper understanding of the hydrodynamic processes that transport water and its constituents such as living biomass, suspended particles, nutrient masses, and contaminants.

Acknowledgements This work was funded by the Korea Meteorological Administration Research and Development Program under grant RACS2009-3004. The authors would like to thank the members of the Earth Environment Prediction Laboratory for their enthusiastic support during the data collection period. AVL acknowledges support from NSF project OCE 090441795. 


\section{REFERENCES}

Alber, M. and J. E. Sheldon, 1999: Use of a date-specific method to examine variability in the flushing times of Georgia estuaries. Estuar. Coast. Shelf Sci., 49, 469482, doi: 10.1006/ecss.1999.0515. [Link]

Atkinson, L. P., J. O. Blanton, and E. B. Haines, 1978: Shelf flushing rates based on the distribution of salinity and freshwater in the Georgia Bight. Estuar. Coast. Mar. Sci., 7, 465-472, doi: 10.1016/0302-3524(78)90123-8. [Link]

Bae, D. H., I. W. Jung, and H. Chang, 2008: Long-term trend of precipitation and runoff in Korean river basins. Hydrol. Process., 22, 2644-2656, doi: 10.1002/ hyp.6861. [Link]

Balls, P. W., 1994: Nutrient inputs to estuaries from nine Scottish east coast rivers; Influence of estuarine processes on inputs to the North Sea. Estuar. Coast. Shelf Sci., 39, 329-352, doi: 10.1006/ecss.1994.1068. [Link]

Banas, N. S. and B.M. Hicky, 2005: Mapping exchange and residence time in a model of Willapa Bay, Washington, a branching, macrotidal estuary. J. Geophys. Res., 110, C11011, doi: 10.1029/2005JC002950. [Link]

Bell, C., J. M. Vassie, and P. L. Woodworth, 1999: POL/ PSMSL Tidal Analysis Software Kit 2000 (Task-2000), Permanent Service for Mean Sea Level, CCMS Proudman Oceanographic Laboratory, Bidston Observatory, Birkenhead, UK, 20 pp.

Bricelj, V. M. and D. J. Lonsdale, 1997: Aureococcus anophagefferens: Causes and ecological consequences of brown tides in U.S. mid-Atlantic coastal waters. Limnol. Oceanogr., 42, 1023-1038.

Chant, R. J., W. R. Geyer, R. Houghton, E. Hunter, and J. Lerczak, 2007: Estuarine boundary layer mixing processes: Insights from dye experiments. J. Phys. Oceanogr., 37, 1859-1877, doi: 10.1175/JPO3088.1. [Link]

Choi, K. W. and J. H. W. Lee, 2004: Numerical determination of flushing time for stratified water bodies. $J$. Mar. Syst., 50, 263-281, doi: 10.1016/j.jmarsys.2004. 04.005. [Link]

de Boer, G. J., J. D. Pietrzak, and J. C. Winterwerp, 2008: Using the potential energy anomaly equation to investigate tidal straining and advection of stratification in a region of freshwater influence. Ocean Model., 22, 1-11, doi: 10.1016/j.ocemod.2007.12.003. [Link]

Dyer, K. R., 1997: Estuaries, A Physical Introduction, $2^{\text {nd }}$ Edition, John Wiley, London, UK, 195 pp.

Eyre, B. and C. Twigg, 1997: Nutrient behaviour during post-flood recovery of the Richmond River Estuary, Northern NSW, Australia. Estuar. Coast. Shelf Sci., 44, 311-326, doi: 10.1006/ecss.1996.0124. [Link]

Garcon, V. C., K. D. Stolzenbach, and D. M. Anderson, 1986: Tidal flushing of an estuarine embayment sub- ject to recurrent dinoflagellate blooms. Estuaries, 9, 179-187.

Huang, W., 2007: Hydrodynamic modeling of flushing time in a small estuary of North Bay, Florida, USA. Estuar. Coast. Shelf Sci., 74, 722-731, doi: 10.1016/j. ecss.2007.05.016. [Link]

Huang, W. and M. Spaulding, 2002: Modelling residencetime response to freshwater input in Apalachicola Bay, Florida, USA. Hydrol. Process., 16, 3051-3064, doi: 10.1002/hyp.1088. [Link]

Ji, Z. G., 2008: Hydrodynamics and Water Quality: Modeling Rivers, Lakes and Estuaries, $1^{\text {st }}$ Edition, John Wiley, New Jersey, USA, 676 pp.

Ji, Z. G., G. Hu, J. Shen, and Y. Wan, 2007: Three-dimensional modeling of hydrodynamic processes in the St. Lucie Estuary. Estuar. Coast. Shelf Sci., 73, 188-200, doi: 10.1016/j.ecss.2006.12.016. [Link]

Kumari, V. R. and I. M. Rao, 2009: Estuarine characteristics of lower Krishna River. Indian J. Mar. Sci., 38, 215-223.

Lebo, M. E., J. H. Sharp, and L. A. Cifuentes, 1994: Contribution of river phosphate variations to apparent reactivity estimated from phosphate-salinity diagrams. Estuar. Coast. Shelf Sci., 39, 583-594, doi: 10.1016/ S0272-7714(06)80011-9. [Link]

Lee, S. W., 2002: Observation report on the river and bay surrounding Gwangyang factory of POSCO, Technical report, Pohang Iron and Steel Company, Korea, $251 \mathrm{pp.}$

Monismith, S. G., S. R. Burau, and M. Stacey, 1996: Stratification dynamics and gravitational circulation in northern San Francisco Bay. In: Hollibaugh, J. T. (Ed.), San Francisco Bay: The Ecosystem, American Association for the Advancement of Science, San Francisco, California, 123-153.

Monsen, N. E., J. E. Cloern, L. V. Lucas, and S. G. Monismith, 2002: A comment on the use of flushing time, residence time, and age as transport time scales. Limnol. Oceanogr., 47, 1545-1553.

Nunes Vaz, R. A., G. W. Lennon, and J. R. de Silva Samarasinghe, 1989: The negative role of turbulence in estuarine mass transport. Estuar. Coast. Shelf Sci., 28, 361-377, doi: 10.1016/0272-7714(89)90085-1. [Link]

Officer, C. B., 1976: Physical Oceanography of Estuaries, Wiley, New York, USA, 465 pp.

Officer, C. B. and D. R. Kester, 1991: On estimating the non-advective tidal exchanges and advective gravitational circulation exchanges in an estuary. Estuar. Coast. Shelf Sci., 32, 99-103, doi: 10.1016/0272-7714 (91)90031-6. [Link]

Pilson, M. E. Q., 1985: On the residence time of water in Narragansett Bay. Estuaries Coasts, 8, 2-14, doi: 10. 2307/1352116. [Link]

Press, W. H., B. P. Flannery, S. A. Teukolsky, and W. T. Vetterling, 1988: Numerical Recipes in C. $1^{\text {st }}$ Edition, 
Cambridge University Press, Cambridge, UK, 768 pp. Shaha, D. C. and Y. K. Cho, 2009: Comparison of empirical models with intensively observed data for prediction of salt intrusion in the Sumjin River estuary, Korea. Hydrol. Earth Syst. Sci., 13, 923-933, doi: 10.5194/ hess-13-923-2009. [Link]

Simpson, J. H., J. Brown, J. Matthews, and G. Allen, 1990: Tidal straining, density currents, and stirring in the control of estuarine stratification. Estuaries Coasts, 13, 125-132, doi: 10.2307/1351581. [Link]

Thomann, R. and J. Muller, 1987: Principle of surface water quality modeling and control. Harper \& Row Publish- ers, New York, 621 pp.

Valle-Levinson, A., 2010: Contemporary Issues in Estuarine Physics. $1^{\text {st }}$ Edition, Cambridge University Press, Cambridge, UK, 326 pp.

Williams, B. L., 1986: Flushing time calculations for the Upper Waitemata Harbour, New Zealand. N. Z. J. Mar. Freshw. Res., 20, 455-465, doi: 10.1080/002883 30.1986.9516165. [Link]

Yanagi, T. and R. Abe, 2005: Increase in water exchange ratio due to a decrease in tidal amplitude in Ariake Bay, Japan. Cont. Shelf Res., 25, 2174-2181, doi: 10.1016/ j.csr.2005.08.019. [Link] 